\title{
Junior doctors' training in the theory and the practice of electroconvulsive therapy
}

\author{
Richard Duffett and Paul Lelliott
}

\begin{abstract}
Recent advances in knowledge about effective administration of electroconvulsive therapy (ECT) has placed great emphasis on the importance of good training and supervision of those administering it. The American Psychiatric Associaton requires that doctors be specifically accredited before they are allowed to give ECT. In England and Wales training is much more informal and ECT is often given by junior doctors. Doctors rostered to administer ECT in Wales and in two areas of England were surveyed as part of the College's third audit of ECT. About two-thirds of respondents were at senior house officer level. The training in ECT appeared of variable quality and one-half had not been supervised by an experienced psychiatrist on the first occasion they administered ECT. Responses to exam-type questions revealed that $45 \%$ lacked knowledge about one or more basic issue related to effective administration of ECT.
\end{abstract}

Recent research has shown that the passage of an electric current just sufficient to induce a seizure during electroconvulsive therapy (ECT) may be inadequate for maximally effective therapy: the current should be $50 \%$ or more above the seizure threshold (the minimum current required to induce a seizure) for bilateral ECT and $200 \%$ above in unilateral ECT. Furthermore the seizure threshold, and therefore the optimal current, varies according to patients' age, gender, medication, previous ECT treatments and other individual factors (Sackeim. 1991). For maximal efficacy and minimal sideeffects those administering ECT should fully understand these findings and have access to, and training in the use of, appropriate equipment. This new knowledge about ECT has led to a revision of guidelines on its administration, both in the UK (Royal College of Psychiatrists, 1995) and in the US (American Psychiatric Association, 1990).

To ensure quality of practice, the American Psychiatric Association (APA) requires that a psychiatrist receive special training and is accredited prior to delivering ECT unsupervised (APA, 1990). In England and Wales, training and supervision in ECT are less formal and ECT is usually administered by junior psychiatrists working to a roster. The ECT Handbook (Royal College of Psychiatrists, 1995) states that junior doctors should observe ECT prior to giving it themselves, and that they should be supervised by an experienced psychiatrist on the first few occasions that they administer it.

Over the past 20 years, the Royal College of Psychiatrists has conducted three large-scale audits of ECT. As part of the third audit, conducted by the College Research Unit, 33 ECT clinics in the old North-East Thames and East Anglian Regions, previously audited in 1991 (Pippard, 1992), were revisited as well as 17 clinics in Wales. The knowledge, training and supervision of junior doctors administering ECT were systematically evaluated to gauge the extent to which they were equipped to deliver ECT effectively.

\section{The study}

A three-part questionnaire was drafted and then piloted by administering it to a small sample of senior house officers (SHOs) and registrars. Part 1 of the questionnaire requests factual information about respondents training and supervision in ECT: Part 2 consists of 19 items. each demanding a true/false response, to assess knowledge about the general management of patients receiving ECT and its effective delivery; Part 3 allows trainees to comment on the training they have received in ECT administration. Doctors who were rostered to give ECT in psychiatric services in Wales and the two English regions were identified and a total of 235 questionnaires despatched.

Returns were analysed with measures derived from the main audit which entailed a visit by R.D. These additional variables were the overall rating of the quality of the ECT clinics (good standards met to a generally acceptable level; average - standards defificient in several areas; poor - some serious deficits) and the extent to which the consultant psychiatrist is involved in 
ECT administration (as measured by the regularity of attendance at ECT sessions). Analysis was performed using the Statistical Package for the Social Sciences for Windows using chisquare or $t$-tests as appropriate.

\section{Findings}

Responses were received from 160 junior doctors (68\% of the total); 58 from Wales $(60 \%$ of the Welsh sample) and 96 from England (69\% of the English sample), 6 (4\% of the total) withheld their location. Of those who replied, $80(50 \%)$ were SHOs in psychiatry and $23(14 \%)$ were general practice vocational trainees (GPVTs) (these two groups often have less than one year's experience of working in psychiatry), 44 (28\%) were registrars in psychiatry (who have more than one year's specialist training and have passed the first part of the College Membership examination); $9(6 \%)$ were non-training grades and $3(2 \%)$ were senior registrars (the latter have passed the full Membership examination).

\section{Training and supervision}

Eighty-five per cent ( $n=136)$ of respondents reported that they had read at least one journal paper on ECT, $63 \%(n=100)$ that they had seen the College video on ECT and $79 \%(n=126)$ that they had received some training on ECT in their present post. However, only $53 \%(n=83)$ reported that they had been supervised by a psychiatrist who was a Member of the College for the first treatment they had administered.

\section{Knowledge of ECT}

Despite piloting, two questions in Part 2 of the questionnaire proved open to misinterpretation and were excluded from subsequent analysis. Table 1 is a summary of the remaining 17 questions and the replies. The mean score of respondents was $60 \%$ (s.d. $=22)$ when the questionnaire was analysed using the College Membership examination method of awarding a mark for a correct answer and deducting one for an incorrect answer. There were no significant differences between mean scores of respondents from the three areas. The more experienced doctors (staff grade, registrars and senior registrars) scored higher than less experienced doctors (SHOs and GPVTs) $(69 \%$ v. $56 \%$, t-test $P<0.001)$. This difference was accounted for by a greater knowledge of issues relating to the general management of patients receiving ECT (first seven questions of Table $1,78 \% v .53 \%, t-$ test $P<0.02$ ); there was no significant difference between grades on knowledge of issues specific to the actual delivery of ECT (last 10 questions of Table $1,63 \% v$. 57\%, $t$-test NS).
There was no association between the ratings of the overall quality of clinics and the scores of the doctors working here. Although junior doctors' knowledge was not closely associated with the regularity with which a consultant attended clinics for the whole cohort, it is notable that the seven junior doctors working in the only two clinics where a consultant attended almost every session scored significantly higher $(78 \%$ v. $56 \%$. $t$-test $P<0.02)$ than the rest.

Forty-eight doctors $(30 \%)$ commented on their training. Of these, 15 (from 12 clinics) praised the recent training they had received and commented favourably on the level of consultant supervision; 23 (from 16 clinics) were wholly critical and 10 (from 6 clinics) had mixed views. The most common complaints were of poor consultant supervision and a fallure to teach both theoretical and practical aspects of ECT.

\section{Comments}

The previous audits of ECT practice by Pippard (1981 \& 1992), also noted that the training of doctors administering ECT was poor and it therefore seems unlikely that practice will greatly improve simply in response to the latest handbook. This audit demonstrates that, despite the College's recent initiatives to improve practice and 17 years of audit, ECT is still often being delivered by inadequately trained personnel. This is perhaps not surprising given that twothirds of doctors on ECT rosters were SHOs or GPVTs (most of whom would have been in their first year of specialist psychiatry training). Of particular concern are the $45 \%$ of doctors who answered incorrectly one or more of the first three questions pertaining to the delivery of ECT which are considered by the authors to be essential knowledge for anyone administering ECT.

Although numbers were small, it is striking that the junior doctors in the only two clinics which were genuinely consultant-led had significantly greater knowledge (these clinics were also the only two judged exemplary on the overall rating). Unfortunately, these clinics were the exception. Most of the rest followed the traditional British system of delegating responsibility for ECT administration to junior doctors on rotation. This means that as many as 10 different doctors may be on the ECT roster at any one time, that there will be a high turnover of doctors as they move on rotation to other hospitals and that a high proportion of administering doctors will be in their first or second job. Unless this system is changed it will remain difficult to assure the quality of training and supervision in ECT or to introduce a comprehensive national accreditation scheme, similar to that of the APA. 
Table 1. Answers to multiple choice questions (\%); correct answers in bold

\begin{tabular}{|c|c|c|c|}
\hline & True & Faleo & Don't know \\
\hline \multicolumn{4}{|l|}{$\begin{array}{l}\text { Guestions related to the management of patients } \\
\text { receiving ECT }\end{array}$} \\
\hline $\begin{array}{l}\text { Recovery after two to three ECT treatments is likely to be a } \\
\text { placebo response }\end{array}$ & 12 & 87 & 1 \\
\hline $\begin{array}{l}\text { ECT is useful for the negative symptoms of schizophrenia } \\
\text { but not positive symptoms }\end{array}$ & 30 & 63 & 7 \\
\hline $\begin{array}{l}\text { ECT is the treatment of choice in those under } 18 \text { years old } \\
\text { with schizophrenia }\end{array}$ & 4 & 91 & 5 \\
\hline Cognitive deficits can last for more than 48 hours post-ECT & 92 & 7 & 1 \\
\hline $\begin{array}{l}\text { Maintenance antidepressants should be used after a } \\
\text { course of ECT even if the patient had previously } \\
\text { failed to respond }\end{array}$ & 96 & 3 & 1 \\
\hline $\begin{array}{l}\text { ECT is contraindicated in patients taking anticonvulsant } \\
\text { drugs or suffering with epilepsy }\end{array}$ & 15 & 81 & 4 \\
\hline $\begin{array}{l}\text { Patients on a Section } 2 \text { are not able to consent to ECT } \\
\text { Questions related to the delivery of ECT }\end{array}$ & 38 & $\mathbf{5 8}$ & 4 \\
\hline The seizure threshold increases during a course of treatment & 88 & 11 & 1 \\
\hline $\begin{array}{l}\text { Selzure threshold is usually higher in old men than } \\
\text { young women }\end{array}$ & 60 & 36 & 4 \\
\hline $\begin{array}{l}\text { For ECT a convulsion and not just an electric current is } \\
\text { required }\end{array}$ & 93 & 6 & 1 \\
\hline A fit of about 5 minutes duration is desirable & 2 & 98 & 0 \\
\hline Pre-oxygenation shortens convulsions & 10 & 87 & 3 \\
\hline The motor fit does not exactly correlate with the EEG & 88 & 9 & 3 \\
\hline $\begin{array}{l}\text { Benzodiazepines can be helpful in delirious patients post- } \\
\text { ictally }\end{array}$ & 42 & 46 & 12 \\
\hline $\begin{array}{l}\text { Right unilateral treatment is preferred for most right } \\
\text { handed patients (if unilateral treatment is given) }\end{array}$ & 82 & 13 & 5 \\
\hline $\begin{array}{l}\text { A fit should be timed from when a bilateral convulsion } \\
\text { is first observed }\end{array}$ & 45 & $\mathbf{6 3}$ & 2 \\
\hline Neuroleptics raise the seizure threshold & 23 & 74 & 3 \\
\hline
\end{tabular}

\section{References}

american Psychiatric association (1990) The Practice of Electroconvulsive Therapy: Recommendations for Treatment. Training and Privileging. Washington. DC: APA.

PIPPARD, J. (1992) Audit of electroconvulsive treatment in two national health service regions. British Journal of Psychiatry. 160, 621-637.

- \& ELAM, L. (1981) Electroconvulsive treatment in Great Britain. British Journal of Psychiatry, 139, 563-568.

Sackeim. H. A.. Devanand, D. P. \& Prudic. J. (1991) Stimulus intensity, seizure threshold, and seizure duration: impact on the efficacy and safety of electroconvulsive therapy. Psychiatric Clinics of North America, 14, 803-843.

ROYAL COLLEGE OF PSYCHIATRISTS (1995) The ECT Handbook: The Second Report of the Royal College of Psychiatrists' Special Committee on ECT. (Council Report CR39). London: Royal College of Psychiatrists.

*Richard Duffett, Clinical Research Fellow and Paul Lelliott, Director, College Research Unit, 11 Grosuenor Crescent, London SWIX 7EE

*Correspondence 